\title{
ANNOUNCEMENTS
}

\section{THE ROYAL COLLEGE OF PATHOLOGISTS London}

One-day symposium

\author{
SAFE FOOD AND THE CHALLENGE OF \\ COOK CHILL CATERING \\ Tuesday, 16 May 1989 \\ at the \\ Royal College of Physicians \\ 11 St Andrew's Place \\ Regent's Park, London NW1
}

This symposium is open to members of the College, to trainee pathologists and to workers in other disciplines with an interest in medical microbiology.

Further details and application forms may be obtained from:

Scientific Meetings Officer

Royal College of Pathologists

2 Carlton House Terrace

London SW1Y 5AF

(Tel: 01-930-5861)

The 159th meeting of the

\section{PATHOLOGICAL SOCIETY OF GREAT BRITAIN AND IRELAND}

will be held at the UNIVERSITY OF ABERDEEN

on July 5 th, 6 th and 7 th, 1989

Microbiology Programme (provisional)

Wednesday, July 5th a.m. Symposium-Pseudomonas - current problems.

Overview of pseudomonas infections; Mechanisms of pathogenicity; Melioidosis;

Antibiotic resistance; Cystic fibrosis.

p.m. Posters and free papers.

Thursday, July 6th a.m. Symposium-Emerging zoonoses.

Salmonella ; Listeria; Anthrax; Borrelia ; Bovine spongiform encephalopathy. p.m. Posters and free papers.

Further information may be obtained from the Meetings Secretary:

Professor E. Mary Cooke, Central Public Health Laboratory, Division of Hospital Infection, 61 Colindale Avenue, London NE9 5HT.

Tel: 01-200-4400 Ext 4249. 
The SIXTH BIENNIAL SYMPOSIUM ON ANAEROBES

of the Anaerobe Discussion Group.(Ltd)

will be held at CHURCHILL COLLEGE, CAMBRIDGE

on Thursday, July 20th-Saturday, July 22nd, 1989

$\underline{\text { Programme }}$

Thursday, July 20th Registration and reception.

Friday, July $21 \mathrm{st} \quad$ a.m. Anaerobic mycoplasmas and protozoa. Paediatric anaerobic infections.

p.m. Anaerobes and the food industry. Poster session.

ADG Dinner.

Saturday, July 22nd a.m. Virulence factors of anaerobes. Molecular studies on anaerobes.

p.m. Rapid diagnosis of anaerobic infections.

Each session will include keynote presentations, free papers and discussion. Contributions are invited for the free papers and for the open poster session.

Further information and registration forms may be obtained from:

Conference Contact,

42 Devonshire Road,

Cambridge, CB1 2BL

\section{PATHOLOGICAL SOCIETY FELLOWSHIP}

The Pathological Society of Great Britain and Ireland is sponsoring a small number of Fellowships to members of the medical and scientific professions working in UK or Ireland in experimental and/or pathologically or microbiologically-related medical research to visit other institutions for periods up to 12 months to learn new investigative techniques. Preference will be given to those requiring additional funds to augment existing salary. Further details and application forms from Professor R. B. Goudie, Department of Pathology, Royal Infirmary, Glasgow G4 0SF. 